\title{
PENGARUH KUALITAS SARANA PRASARANA TEMPAT GYM TERHADAP TINGKAT KEPUASAN KONSUMEN DI GARUDA FITNESS KOTA SELONG
}

\author{
Muhamad Zainul Muhlis ${ }^{1}$, Hariadi $^{2}$, Mahfuz ${ }^{3}$ \\ email: mukhlis7311@gmail.com ${ }^{1}$, hariadi121113@gmail.com², mahfuzmahfuz75@gmail.com ${ }^{3}$ \\ 1,2,3 Pendidikan Jasmani Kesehatan Dan Rekreasi Fakultas Ilmu pendidikan Universitas Hamzanwadi
}

\begin{abstract}
Abstrak
Penelitian ini bertujuan untuk mengetahui pengaruh kualitas sarana prasarana terhadap tingkat kepuasan konsumen dalam melakukan gym di Garuda fitness. Penelitian ini merupakan penelitian kuantitatif dengan menggunakan metode survey. Dalam penelitian ini menggunakan teknik probability sampling. Sampel penelitian ini 30 member Garuda Fitness. Teknik pengumpulan data menggunakan angket dengan pengukuran skala likert 5 , dari skor 1-5. Bedasarkan hasil analisa data dan pembahasan dapat diambil kesimpulan, bahwa tingkat kepuasan konsumen terhadap kualitas sarana prasarana merupakan sangat puas dengan presentase $(82,79 \%)$. Adapun tingkat kepuasan masing-masing aspek sebagai berikut, pada kategori sangat puas pada aspek bukti fisik $(81,44 \%)$, kehandalan $(84 \%)$, daya tanggap (82\%), empati $(86,8 \%)$, keputusan konsumen $(85,17 \%)$, sedangkan katagori puas merupakan aspek jaminan (77,33\%). Maka dapat disimpulkan tingkat kepuasan secara keseluruhan sangat puas.
\end{abstract}

Kata Kunci: Sarana prasarana, Kepuasa

\section{Abstract:}

This study aims to know the influence of the quality of infrastructure towards the level of customer satisfaction in doing gym at Garuda fitness. This study was quantitative using the survey method. This study used probability sampling techniques. The sample of this study was 30 members of Garuda fitness. The data collection techniques used questionnaires with 5 Liker scale measurements, from scores 1-5. Based on the results of data analysis, and the discussion can be concluded, that the level of customer satisfaction with the quality of infrastructure was very satisfied with the percentage (82.79\%). The level of satisfaction of each aspect is as follows, in the very satisfied category are aspects of physical evidence $(81.44 \%)$, reliability (84\%), responsiveness $(82 \%)$, empathy $(86.8 \%)$, consumer decisions $(85.17 \%)$, while the satisfied category is the guarantee aspect $(77.33 \%)$. So it can be concluded that the overall level of satisfaction is very satisfied.

Keywords: Boomerang Run Training, Dribbling skills, Futsal Games

\section{A. Pendahuluan}

Olahraga pada dasarnya merupakan kebutuhan setiap manusia dalam kehidupan agar kondisi fisik dan kesehatannya tetap terjaga dengan baik. Menurut Husdarta (2016: 150), olahraga digunakan untuk segala jenis kegiatan fisik, yang dapat dilakukan di darat, air, dan udara. Olahraga memainkan peranan yang berarti dalam kehidupan budaya seluruh masyarakat. Namun kehidupan pada masa sekarang ini, menuntut manusia akan lebih banyak menghabiskan waktunya untuk bekerja, sehingga olahraga menjadi sesuatu yang jarang dilakukan. Kesadaran masyarakat akan pentingnya olahraga pada masa sekarang ini membuat 
masyarakat mulai tertarik untuk mendatangi pusat-pusat penyedia jasa di bidang olahraga. Kebutuhan akan kesehatan menjadi suatu hal yang sangat penting dan berharga dalam kehidupan manusia. Oleh karena itu, manusia ingin berusaha menjaga kesehatannya dan salah satu cara agar kesehatan tetap terjaga dengan baik adalah melalui berolahraga. Dalam menjaga kebugaran jasmani, seseorang perlu melakukan latihan secara rutin dan teratur. Latihan merupakan proses kerja yang dilakukan secara sistematis dan berkesinambungan. Beban atau intensitasnya semakin hari semakin bertambah agar memberikan rangsangan secara menyeluruh terhadap tubuh. Hal ini bertujuan untuk meningkatkan kemampuan fisik dan mental secara bersama-sama. Selain itu, latihan kebugaran jasmani bisa diartikan dengan jenis latihan fisik (jasmani) melalui gerakan-gerakan anggota tubuh atau gerakan tubuh secara keseluruhan, dengan maksud untuk meningkatkan dan mempertahankan kebugaran jasmani. Hal ini menandakan bahwa aktivitas manusia semakin berat, sehingga untuk menjaga kebugaran jasmani/fisik seseorang tidak dapat terpenuhi dengan baik. Garuda fitness merupakan salah satu penyedia jasa pusat kebugaran yang ada di kota selong, akan tetapi di garuda fitness ada beberapa sarana dan prasarana yang kurang mendukung, seperti ruangan, loker yang rusak, tempat parkir yang sempit, alat yang tersedia terbatas, dan ada beberapa alat yang kurang terawat sehingga mengganggu kenyaman konsumen. Berdasarkan pemaparan di atas, dapat disimpulkan bahwa penting dalam memperhatikan kualitas sarana prasarana yang disediakan, untuk meningkatkan minat konsumen dalam mengggunakan jasa di garuda fitness. Sehingga inilah yang menarik penulis mengadakan penelitian, yaitu tentang pengaruh kualitas sarana prasarana terhadap tingkat kepuasan konsumen dalam melakukan gym di Garuda fitness.

\section{B. Metode}

Penelitian tentang kualitas sarana prasarana tempat gym terhadap tingkat kepuasan konsumen di garuda fitness merupakan penelitian deskriptif dengan menggunakan metode survei, adapun pengumpulan datanya dengan menggunakan angket. Menurut Asnawi (2011: 30), metode survei adalah penyelidikan yang diadakan untuk memperoleh fakta-fakta dari gejala-gejala yang ada dan mencari keterangan-keterangan secara faktual, baik tentang institusi sosial, ekonomi, atau politik, dari suatu kelompok atau suatu daerah. Penelitian ini dilaksanakan disalah satu penyedia jasa tempat gym yang bertempat di Garuda fitness, yang bertempat dipuasat pertokoan pancor kota selong. Pelaksanaan penelitian kuantitatif deskriptif ini dilaksanakan pada 21 Februari s/d 12 Maret 2019. Sampel penelitian dalam penelitian ini adalah member fitness center di Garuda fitness yang berjumlah 30 orang. Dalam penelitian ini teknik yang digunakan dalam pengambilan sampel dengan teknik probability sampling yaitu teknik pengambilan sampel yang memberikan peluang yang sama bagi setiap unsur (anggota) populasi untuk dipilih menjadi anggota sampel (Sugiono 2018: 82). Variabel Penelitian Menurut Sugiono (2018:39), Variabel penelitian adalah suatu atribut atau sifat atau nilai dari orang, obyek atau kegiatan yang mempunyai variasi tertentu yang ditetapkan oleh peneliti untuk di pelajari dan kemudian ditarik kesimpulanya. Dalam penelitian ini ada dua jenis variabel yaitu variabel independen dan variabel dependen. Teknik Pengumpulan Data, 1).Kuesioner/angket Menurut Sugyiono (2018: 142), kuesioner/angket adalah teknik pengumpulan data yang dilakukan dengan cara memberi seperangkat pertanyaan atau pernyataan tertulis kepada responden. 2).Observasi Menurut Sugiono (208:145), menyatakan bahwa observasi adalah suatu proses yang kompleks, suatu proses yang tersusun dari berbagai proses biologis maupun psikologis. Dua diantaranya yang terpenting adalah proses-proses pengamatan dan ingatan. Instrumen Pengumpulan Data Instrumen yang digunakan dalam penelitian ini merupakan kuesioner/ angket. Angket tersebut berisi butir-butir pernyataan untuk diberi tanggapan oleh responden. Menurut Prasetyo (2015: 29), angket adalah daftar pernyataan atau pertanyaan yang dikirimkan kepada 
responden baik secara langsung atau tidak langsung. Analisis data merupakan setelah data dari seluruh responden terkumpul. Dalam penelitian ini, teknik analisis data menggunakan teknik analisis deskriptif yang kemudian di maknai. Menurut Sugiono (2018: 147), skala Likert Untuk menghindari kecenderungan responden asal isi dan memilih skor tengah dari skala yang digunakan, maka peneliti menggunakan skala 5. Jawaban setiap item instrument menggunakan Skala Likert mempunyai gradasi dari sangat positif sampai sangat negatif. Skalanya sebagai berikut (Sugiono, 2018: 93):

\section{Hasil Penelitian Dan Pembahasan}

Untuk mengetahui tingkat kepuasan konsumen terhadap kualitas sarana prasarana tempat gym di garuda fitness diukur berdasarkan indikator bukti fisik/ bukti langsung, kehandalan, daya tanggap, jaminan, empati, keputusan konsumen. Dari indikator tersebut kemudian dikembangkan kedalam 30 butir pertanyaan, dengan 5 alternatif tanggapan atau respon, kemudian di skor mulai 1 hingga 5. Berdasarkan data yang diperolah dari 30 konsumen sebagai responden skor maksimal empirik $=140$, dengan skor minimal $=105$, rerata sebesar 124 dan simpangan baku sebesar85,4. Selengkapnya pada diagram batang berikut.

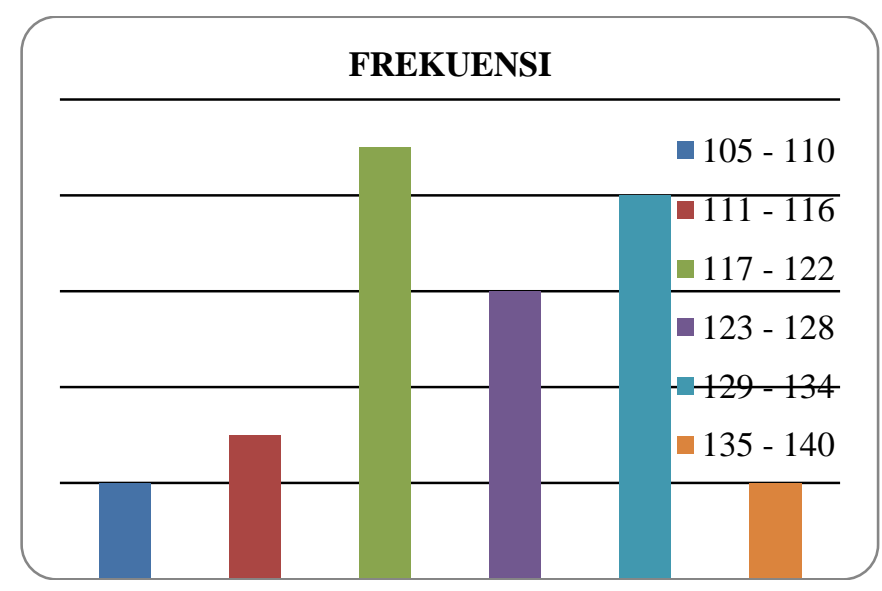

Gambar 1. Histogram Distribusi Frekuensi Kualitas Sarana Prasarana Terhadap Tingkat Kepuasan Konsumen dalam Melaakukan Gym di Garuda Fitness.

Melihat Gambar diagram batang di atas, diperoleh informasi bahwa berjumlah 2 orang pada kelas interval $105-110$, berjumlah 3 orang pada kelas interval $111-116$, berjumlah 9 orang pada kelas interval $117-122$, berjumlah 6 orang pada kelas interval $124-128$, berjumlah 8 orang pada kelas interval 129 134, berjumlah 2 orang pada kelas interval $135-140$. Histogram distribusi frekuensi kualitas sarana prasarana terhadap tingkat kepuasan konsumen dalam melakukan gym di Garuda fitness: Selanjutnya perlu mengetahui presentase antara jumlah skor empirik terhadap jumlah skor harapan tiap-tiap aspek kepuasan. Jumlah skor empirik diperoleh dari jumlah skor yang didapatkan. Pada aspek bukti langsung yang memiliki 6 butir, dengan penskoran maksinal adalah 5, dan jumlah responden $(\mathrm{n})=30$, jumlah skor harapan sebesar $(6 \times 5 \times 30)=900$. Oleh karena skor empirik sebesar 733, maka presentase jumlah skor empirik terhadap harapan adalah $(733 / 900) \times 100 \%=81,44 \%$. Selengkapnya pada tabel 4.1 . 
Tabel 1. Persentase Pencapaian Tiap Aspek Kepuasan Konsumen Terhadap Kualitas Sarana Prasarana Tempat Gym di Fitness Center Kota Selong Variabel X dan Y.

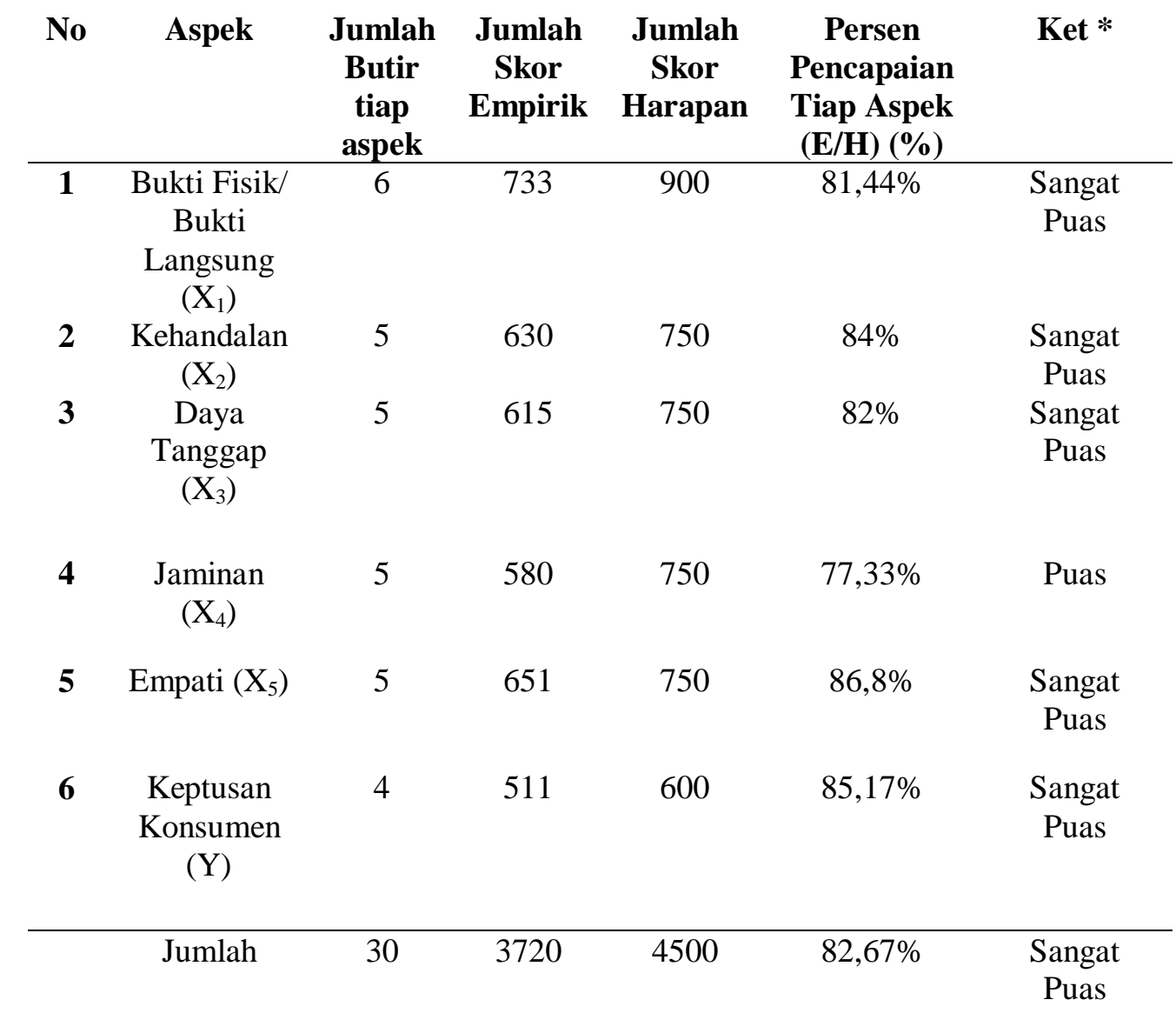

*) $\mathrm{SP}=$ Sangat Puas

Berdasarkan tabel 4.1, diperoleh informasi bahwa persentase antara jumlah skor empirik terhadap jumlah skor harapan tiap-tiap aspek kepuasan.Pada kategori sangat puas adalah bukti langsung/ bukti fisik $(81,44 \%)$, kehandalan (84\%), daya tanggap (82\%), empati $(86,8 \%)$, keputusan konsumen $(85,17 \%)$, sedangkan katagori puas adalah aspek jaminan $(77,33 \%)$. Secara keseluruhan atau secara umum persentasekepuasan sebesar $82,67 \%$ dengan kategori "sangat puas". Berdasarkan hasil penelitian diperoleh dengan taraf signifikansi $0,05 \%$ nilai t hitung 2,779> t tabel 1,699, maka hipotesisnya berbunyi " Ada Pengaruh Kualitas Sarana Prasarana Tempat Gym Terhadap Tingkat Kepuasan Konsumen di Garuda Fitness Kota Selong”.

\section{Simpulan}

Bedasarkan hasil penelitian yang telah disajikan dalam uraian pada bab sebelumnya, maka dapat dikemukakan beberapa kesimpulan antara lain:

1. Berdasarkan hasil analisis data, deskripsi hasil penelitian, dan pembahasan, dapat diambil kesimpulan, bahwa tingkat kepuasan konsumen terhadap sarana prasarana tempat gym di garuda fitness kota selong adalah sangat puas dengan presentase $(82,79 \%)$. Adapun tingkat kepuasan masing-masing faktor sebagai berikut, pada kategori sangat puas adalah bukti fisik $(81,44 \%)$, kehandalan (84\%), daya tanggap (82\%), empati (86,8\%), keputusan konsumen $(85,17 \%)$, sedangkan katagori puas adalah aspek jaminan $(77,33 \%)$.

2. Adapun hasil penelitian diperoleh dengan taraf signifikansi $0,05 \%$ nilai t hitung 2,779> $\mathrm{t}$ tabel 1,699, maka hipotesisnya berbunyi “ Ada Pengaruh Kualitas Sarana Prasarana 
Tempat Gym Terhadap Tingkat Kepuasan Konsumen di Garuda Fitness Kota Selong”. Ada bebrapa saran yang perlu disampaikan sehubungan dengan hasil penelitian ini, antara lain: (1) Agar mengembangkan penelitian lebih dalam lagi tentang tingkat kepuasan (bukti fisik/ bukti langsung, kehandalan, daya tanggap, jaminan, empati, dan kepuasan konsumen) yang menggunakan sarana prasarana tempat gym di garuda fitness kota selong. (2) Agar mengembangkan penelitian lebih dalam lagi tentang tingkat kepuasan (bukti fisik/ bukti langsung, kehandalan, daya tanggap, jaminan, empati, dan kepuasan konsumen) yang menggunakan sarana prasarana tempat gym di garuda fitness kota selong dengan menggunakan metode lain.

\section{Daftar Pustaka}

Asnawi, dkk. (2011). Metodelogi Riset Manajemen Pemasaran.Malang: UIN Maliki Press (Anggota IKAPI).

Husdarta. (2016). Sejarah dan Filsafat Olahraga.Bandung: Alfabeta.

Tim. (2016). Pedoman dan Penulisan Tugas Akhir.Universitas Hamzanwadi.

Nasucha,yakub.(2015).Bahasa Indonesia Untuk Penulisan Karya Tulis Ilmiah. Yogyakarta: Media Perkasa.

Sugiyono. (2018). Metode Penelitian Kuantitatif, Kualitatif, dan R\&D. Bandung: Alfabeta. . (2017). Metode Peneleitian Kualitatif.Bandung: Alfabeta (2017). Statistika Untuk Penelitian.Bandung: Alfabeta. 